\title{
Amor romântico na literatura infantil: uma questão de gênero
}

\section{Romantic love in children's literature a gender question}

\author{
Suyan Maria Ferreira Pires*
}

\begin{abstract}
RESUMO
Ao considerar que o amor e o casamento estão sendo postos em xeque em nossa sociedade, na medida em que surgem novas configurações familiares, ou mesmo outras possibilidades de se vivenciar o sentimento amoroso, este artigo centra-se em discutir como a literatura infantil vem apresentando esses temas, a saber: como o amor romântico e a materialização deste sentimento, através das relações que se estabelecem a partir dele, têm sido representados nos livros de literatura infantil? De que forma as relações de gênero são veiculadas nessas obras? Como o casamento é visto na vinculação com as relações amorosas? Os resultados apontam que na maior parte das obras literárias infantis o sentimento amoroso ainda aparece associado à ideia de casamento; à mulher fica a responsabilidade da criação dos/as filhos/as; algumas histórias apresentam o amor romântico coligado à dor e à dificuldade de conquista. Também são recorrentes as características de amor à primeira vista e o empoderamento desse sentimento em transformar o outro.

Palavras-chave: amor romântico; literatura infantil; relações de gênero; representação.
\end{abstract}

\begin{abstract}
Considering that love and marriage have being jeopardized in our society, as new family patterns or even other possibilities on how to experience love emerge, my research problem is focused on discussing how children's literature has been presenting themes such as: how does romantic love and the materialization of this feeling, through relationships that are established

* Doutora em Educação - UFRGS. E-mail: suyanzen@hotmail.com
\end{abstract}


based upon it, have been represented in children's literature books? In which ways are gender relationships depicted in these books? How is marriage seen in connection with love relationships? Results show that in most of children's literary pieces love feelings still appears associated with the idea of marriage; woman is still responsible for raising up children; some stories present romantic love linked with pain and the difficulty of conquest. The characteristics of love at first sight are also persistent, as well as the empowerment of this feeling in order to transform the other person.

Keywords: children's literature; romantic love; gender relationships; representation.

Um dos aspectos que caracteriza a contemporaneidade, também chamada de pós-modernidade ${ }^{1}$, é um estado de permanente conflito na sociedade e nos laços entre e dentro de seus segmentos. Na verdade, a pós-modernidade não gerou essa crise; ela a herdou da Modernidade e a explicita em cores cada vez mais fortes. A pós-modernidade se constitui como uma crítica à modernidade, sem substituí-la, contudo. Nela convivem elementos do classicismo, da modernidade e da própria pós-modernidade, com sua dimensão de conflito permanente, sem que se forme um todo, sem que se integrem.

É ambíguo o momento em que vivemos. Por um lado experimentamos a satisfação de podermos modificar nosso mundo social, no qual novas identidades culturais e sociais surgem, enquanto outras já existentes são transgredidas, arrombadas, deliciosa ou sofridamente transformadas. Por outro lado, nosso tempo é de dor, de angústia, de incertezas, de um mundo à deriva. Uma parcela cada vez maior da humanidade é excluída dos prazeres e das alegrias da vida. É época de primazia de mercado, de competitividade, de produção, de privatização e desregulamentação. Ao mesmo tempo é o momento de investidas na coletividade, no crescimento grupal, na valoração do trabalho em equipe.

Do ponto de vista econômico, a pós-modernidade acompanhou e favoreceu um considerável empobrecimento geral e um aumento apreciável do número de excluídos dos bens e do bem viver em todo o mundo. Consumo é a palavrachave dessa nova era e os sujeitos se transformam em consumidores incessantes. A pós-modernidade também adentrou o cotidiano da vida das pessoas através da tecnologia eletrônica de massa. Assim, os meios de comunicação aderiram à função de "interligar" o mundo às diferentes realidades, favorecendo, assim, a chamada globalização.

1 Sobre este tema ler Stuart Hall (1997, 1998); Michael Peters (2000). 

sociedade

Nessa linha de pensamento, Antonio Dória (2008, p. 30) afirma que nossa sociedade

urbana e industrializada, defini-se pela competição acirrada. A competição sempre existiu, mas o modo de produção atual e a conquista de mercados tornaram esse fenômeno mais evidente. Hoje, fala-se de competição até mesmo como algo positivo e necessário. E a industrialização traz exigências como eficiência, rapidez, produção em série e, por extensão, maior controle da natureza e do homem. Nesse contexto de eficiência, a pausa, a interrupção, a dúvida, enfim, poderiam se tornar grandes obstáculos.

Passamos a conviver com situações entendidas muitas vezes como naturais, mas que foram construídas e continuam sendo legitimadas como práticas sociais. Lançamos mão de conceitos novos, abandonamos concepções antigas, apreciamos ideias diferentes, tornamo-nos metamorfoses ambulantes neste mundo do aqui-e-agora. A problematização sobre a possibilidade de tais mudanças termina por propiciar a incerteza, a desconfiança em relação a situações consideradas certeiras, à reflexão sobre os argumentos ditos definitivos, permitindo-se assim que o sujeito situe-se na busca intermitente do novo, do diferente.

Percebemos a multiplicação concomitante de práticas sociais inusitadas, singulares, excêntricas, "censuráveis", lamentosas que colocam na berlinda as "verdades" sociais vividas recentemente. Tal época, borbulha, efervesce, invade diferentes instâncias sociais ao mesmo tempo em que é produzida no âmago dessas. Sob essa perspectiva, pode-se verificar algumas características concentradas nessa cultura instantânea como a busca do prazer imediato, o descompromisso com o outro, a tolerância ao diferente, a (des)construção e transgressão às regras, a violação dos corpos, a banalização de diferentes práticas e a realização de desejos efêmeros.

A representação visual torna-se objeto de fascínio. Cola-se a ela a ideia de produção de estímulos, de possibilidade de emoções, de contemplação de cenas virtuais, fantásticas, delirantes, violentas, de forte apelo à sexualidade, tornando os sujeitos espectadores e produtores da realidade. Passa-se, portanto, a conviver com os fatos sociais cotidianos estáveis ao tempo de suas imagens.

E nessa sociedade em constante crise, com rupturas, com desconstruções das "verdades únicas" na qual o controle social se exerce através das informações, da estetização, da personalização do cotidiano, questiono: ainda há espaço para o amor? Se há, de que amor estamos falando? De um amor romântico, 
repentino, perene? De um amor fugaz, abrasante, momentâneo? De um amor sereno, gentil, pacífico?

Na sociedade ocidental, esse sentimento é muito valorizado e o discurso que o circunda traz sempre a ideia de que "sem amor estamos amputados de nossa melhor parte. A vida pode até ser mais tranqüila e livre de dores quando não amamos. [...] Diante dele (do amor) tudo empalidece; sem ele, até o que engrandece perde a razão de ser" (COSTA, 1998, p. 11).

Dessa forma, quem ama procura um par, pois em todo amor há pelo menos dois seres envolvidos e, quando correspondido, pode ser estabelecida uma relação. A partir de então nota-se uma tênue fronteira entre o sentimento e a forma de gerenciá-lo, que comumente é implacável. Uma vez constituída essa relação, pode-se perceber o sentimento de amor dos apaixonados sendo vivido, abundantemente, com o desenrolar das situações. Nessas situações, as promessas de amor são menos ambíguas do que suas dádivas. Assim, a tentação de se apaixonar, tão divulgada e legitimada em nossa sociedade, é grande e poderosa, pois "aprendemos a crer que amar romanticamente é uma tarefa simples e ao alcance de qualquer pessoa razoavelmente adulta, madura, sem inibições afetivas ou impedimentos culturais" (COSTA, 1998, p. 35).

E está justamente aí a fragilidade do amor, a qual se ocupa em suportar a vulnerabilidade das relações entre os amantes. Ora, se o amor exprime a vontade de cuidar e de preservar o objeto cuidado, como pode tal relação subjugar os parceiros nela envolvidos?

Talvez, de modo incomum, em um mundo obcecado pela segurança, os apaixonados exigem do sentimento de amor uma estabilidade pouco possível de ser concretizada. Dessa forma, a atração, o desafio e a sedução passam a ser elementos constitutivos das relações amorosas românticas. Pode-se citar, ainda, as promessas de compromisso a curto e longo prazo como características da materialização desse amor tornando-o excludente e possessivo, pois estar em um relacionamento significa, sobretudo, uma incerteza permanente. Percebese, então, um paradoxo: honrar com o compromisso acordado e o sentimento vivido sem tornar a realidade afrontosa e exasperante. A respeito disso Zygmunt Bauman (2004, p. 29) afirma que

se você investe numa relação, o lucro esperado é, em primeiro lugar e acima de tudo, a segurança - em muitos sentidos: a proximidade da mão amiga quando você mais precisa dela, o socorro na aflição, a companhia na solidão, o apoio para sair de uma dificuldade, o consolo na derrota e o aplauso na vitória; e também a gratificação que nos toma imediatamente quando nos livramos de uma necessidade. 
Sendo assim, se pode dizer que faz parte do discurso do amor romântico promulgar formas que derrotem fontes de incertezas presentes - garantindo assim a segurança - até porque não se sabe o que está pela frente e o que o futuro pode trazer. Junto a essa luta está o esforço despendido pelos amantes a fim de que a relação seja profícua e duradoura, colando à imagem do sentimento amoroso a ideia de imortalidade.

Jane Felipe (2006, p. 11) caracteriza o amor "como romântico quando ele é regido por uma idealização que se estende aos seguintes aspectos: a idéia de intensidade (em si mesmo e no outro, para quem o amor se destina), a concepção de completude, de eternidade e de entrega".

Dessa forma, os enamorados exacerbam o sentimento de amor como se ele fosse o responsável pela felicidade eterna do parceiro e por sua exclusividade. Comumente, escuta-se em músicas, poesias, sonetos, conversas informais, que o outro é o motivo da sua vida, a razão da sua existência, que o sentido de um está na existência e na presença do outro. Assim sendo, há um empoderamento ${ }^{2}$ do sentimento amoroso como algo grandioso, mágico, que atravessa o tempo e o espaço com uma força intensa. Nesse sentido, percebe-se que o ponto nevrálgico paira na forma como o amor romântico é idealizado e materializado nas relações amorosas e não no sentimento em si.

Vale lembrar ainda que cada época tem sua modalidade de amor e de relacionamento e o modo como os costumes e hábitos são produzidos na e pela cultura perpassam décadas e até séculos, naturalizando o que é uma construção histórica. Também é importante lembrar que os hábitos e costumes atuais não invalidam nem são superiores aos de períodos anteriores e, sim, se constroem, se produzem e se reproduzem de forma processual na cultura. A ideia de progresso, de evolução em direção a um aperfeiçoamento era uma ideia da Modernidade.

\section{Histórias e Práticas Sociais}

É importante salientar que as pessoas sempre manifestaram interesse em narrar. Apreciam filmes, novelas de televisão ou romances porque, fundamentalmente, esses gêneros contam uma história. Quando ainda não existiam esses veículos de comunicação, eram as reuniões familiares e comunitárias manifestações primeiras - que assumiam essa função. Várias condições podem

2 Poder atribuído a alguém ou a algo por meio de práticas sociais recorrentes. 
propiciar esse interesse particular que possuímos pelas histórias. Em primeiro lugar, o fato de a própria vida poder ser entendida como uma história - sucessão de acontecimentos e emoções. Um outro motivo, que talvez justifique essa paixão, é a identificação com os sentimentos dos personagens. Para ilustrar tais afirmações, cito um trecho de uma obra de Fanny Abramovich (1997, p. 17, grifo da autora) na qual corrobora que

é através duma história que podemos descobrir outros lugares, outros tempos, outros jeitos de agir e de ser, outra ética, outra ótica... É ficar sabendo História, Geografia, Filosofia, Política, Sociologia, sem precisar saber o nome disso tudo e muito menos achar que tem cara de aula... Porque, se tiver, deixa de ser literatura, deixa de ser prazer e passa a ser Didática, que é outro departamento (não tão preocupado em abrir as portas da compreensão do mundo).

Nesse sentido, pode-se também destacar a história como alimento da imaginação humana: na vida real, os fatos se sucedem rotineiramente; na história, ao contrário, tudo é possível. Inexistem barreiras entre fantasia e realidade.

Dessa forma, as obras literárias entendidas como artefatos culturais legitimadores de identidades sociais e de gênero, estabelecem relações de poder entre leitores/as e escritores/as de tais textos, constituindo um circuito produtor e reprodutor de práticas sociais masculinas e femininas consideradas ideais. Sendo assim, um livro de história infantil como produto cultural e analisado sob a perspectiva na qual fundamento minha tese, pode apresentar características sensíveis em relação a: práticas de significação, relações sociais e subsequentes relações de poder ou ainda, prática produtora de identidades sociais e de gênero.

Quando afirmo que tais aspectos podem estar presentes na literatura, refiro-me às representações de gênero contidas em tais obras com o intuito de negociar, conflitar e, por fim, legitimar identidades masculinas e femininas. É importante ressaltar, aqui, que fundamento minha concepção de representação no pensamento pós-estruturalista e a compreendo como o conjunto de crenças, ideias, opiniões, percepções, etc., enfim, significados sociais atribuídos por uma pessoa ou por um grupo sobre algo ou alguém. Todavia, tais significados são efêmeros, uma vez que estão expostos ao tempo e ao lugar e, assim sendo, eles, constantemente, deslizam e se contrapõem a certezas e interpretações únicas. Dessa forma, as representações são constituídas e reconstituídas na e pela cultura.

Costuma-se dizer que as narrativas constituem uma das práticas discursivas 
mais importantes de nossas vidas. Tomo emprestado o conceito de Foucault (1987, p. 136) sobre prática discursiva: "é um conjunto de regras anônimas, históricas, sempre determinadas no tempo e no espaço, que definiram em uma época dada, e para uma área social, econômica, geográfica ou lingüística dada, as condições de exercício da função enunciativa".

Com essa definição, percebemos o quão efêmero e cambiante é o momento de uma narrativa, pois elas são constituídas de formas diferentes dependendo do momento, do lugar e das pessoas envolvidas. Jorge Larrosa (1996, p. 462) compreende as narrativas, "não apenas como reveladoras de histórias de outros: elas também contam histórias sobre nós e o mundo em que estamos e, neste sentido, nos ajudam a dar sentido, ordem, às coisas do mundo e a estabilizar e fixar nosso eu".

Narrar está estreitamente conectado com a produção de nossas identidades. São nas narrativas, entre outros processos, que variados poderes atuam para fixar as identidades dos grupos tanto privilegiados como desprivilegiados, embora sejam também nas narrativas que esses grupos podem afirmar identidades diferentes daquelas descritas pelas narrativas hegemônicas. Desse modo, as narrativas também contribuem para constituir um mundo onde devemos nos alojar, onde devemos encontrar um lugar.

Ao tomarmos um livro para leitura, por vezes, é de fácil percepção os efeitos de verdade que as representações contidas nele produzem. Tais significados se estabelecem por meio de relações sociais experimentadas no dia-a-dia e registradas na literatura, contribuindo desta forma para um constante ir e vir, reconhecendo que as histórias infantis produzem e são produzidas pela cultura.

Nesse sentido, acredito que as narrativas e as histórias são formas de conhecermos pessoas, de nos localizarmos no tempo, de atribuirmos conceitos, de legitimarmos comportamentos; não são interpretáveis por si sós. Elas pertencem a um contexto e "carregam" consigo histórias anteriores. "Cada pessoa se encontra já imersa em estruturas narrativas que lhe pré-existem e em função das quais constrói e organiza de um modo particular sua experiência, impõe-lhe um significado" (LARROSA, 1999, p. 70).

Dessa forma, pode-se afirmar que as representações são culturalmente construídas, cambiantes e mutáveis, uma vez que são constituídas em um determinado lugar em um certo tempo. Os sujeitos também "negociam" as representações já legitimadas, havendo, assim, trocas, substituições, releituras, construções sucessivas.

Interessante ressaltar, aqui, a afirmação que Silveira (2006, p. 2) faz em relação ao intento dos autores ao escreverem suas obras literárias: 
mesmo a literatura infantil produzida nos anos mais recentes que se pretende "emancipatória" ou "não pedagogizante", "não moralizante", não foge à contingência de carregar consigo representações de mundo, consciente ou inconscientemente nela plasmadas pelo autor, assim como não pode sofisticar demais seus recursos formais, sob pena de ser rejeitada pelo leitor infantil.

Por conta disso, deve-se entender que tanto os/as leitores/as (tomados aqui em seu sentido mais amplo - leitores/as do mundo) como os/as escritores/as são constituintes das culturas e que as representações imagéticas e verbais presentes nas obras literárias podem representar o esperado desejável e o indesejável em uma determinada sociedade, pois ao mesmo tempo em que produzem (os escritores) e legitimam representações sociais em suas histórias, suas histórias são legitimadas e produzidas pelos leitores nas práticas das quais fazem parte.

\section{Algumas ilações}

Os livros de literatura infantil sempre foram e continuam sendo artefatos culturais e, como tais, carregam uma gama de significados que reforçam a cultura de certo tempo e lugar. Dentre esses significados estão as representações de masculinidades e feminilidades e, no caso específico deste artigo, as relações amorosas, que podem ser questionadas e problematizadas pelo público leitor sobre as constituições apresentadas nos respectivos enredos.

Ao mesmo tempo em que as obras legitimam comportamentos, modos de agir, de vestir, de se relacionar, considerados mais tradicionais, também exibem diferentes maneiras do sujeito se constituir, permitindo com isso, espaço na literatura infantil, para outras formas de representações de gênero e de relações amorosas. Nesse sentido, encontrei algumas obras nas histórias infantis contemporâneas que versam sobre situações do cotidiano, tais como: separação, divórcio e a satisfação pelo fato de ser solteira.

Minha abordagem analítica concentra-se na forma como esses temas são apresentados em tais histórias, considerando os textos verbais e imagéticos, na tentativa de perceber de que maneiras as relações amorosas românticas são apresentadas para o público infantil, implicando de forma direta na constituição relacional de gêneros. Nesse caminho, faço questão de frisar que será apenas uma tentativa de interpretação mediante tantas outras possíveis. Também não 
tenho a pretensão de abordar todos os aspectos para os quais as obras se prestam, e sim, minha intenção primeira é desacomodar os/as leitores/as a respeito das práticas sociais aceitas e consideradas como naturais.

A preocupação com as relações amorosas românticas não é privilégio da literatura infantil. Nota-se a presença recorrente delas em outros artefatos culturais como jornais, revistas, músicas, filmes, novelas e outros programas de entretenimento, gerando discussões apaixonadas ou controversas. Além disso, percebe-se na tradição oral o discurso suscitante dirigido aos casais, desde a mais tenra idade, salientando e reforçando as práticas amorosas socialmente esperadas, de forma que o/a opositor/a a tais ideias sinta-se à margem da cultura.

Para este artigo trago a análise da obra A Princesa Sabichona, de Babette Cole, na qual, a protagonista - a princesa - não queria casar, apesar de sua mãe sugerir com veemência que ela assim o fizesse. - "Está na hora de criar juízo"disse sua mãe, a Rainha. - "Chega de só ficar às voltas com esses bichos! Trate de arranjar um marido!". Já se percebe, pelo nome da obra e pelas soluções que Sabichona encontra para se livrar dos pretendentes, que queriam casar com ela por ser rica e bela, o quão inteligente é a personagem e revela rebeldia quando não aceita a educação que lhe é imposta.

Sua fisionomia - na ilustração - retrata seu descontentamento em relação à solicitação da rainha. Interessante verificar que, em nenhum momento da obra, Sabichona considera a possibilidade de

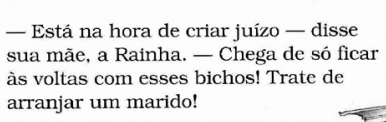
sua mãe, a Rainha. - Chega de só ficar às voltas com esses bichos! Trate de arranjar um marido!

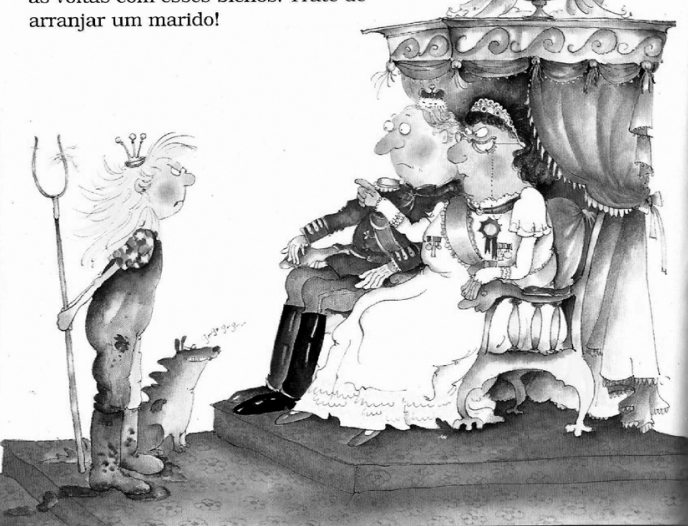
efetivamente casar-se, apenas cria situações de uma perspectiva ilusória de união totalmente abalada quando o candidato não consegue realizar os desafios propostos por ela. Nos contos tradicionais, a princesa não tem papel atuante e decisivo, cabe a ela apenas sonhar com o príncipe, recebê-lo em casamento e serem felizes para sempre. Aqui, ela não aceita esse destino; quer, ao contrário, permanecer solteira, desobedecendo a Rainha, sua mãe.

Sabat (2004, p. 104, grifos da autora), reflete sobre os modos de conduta esperados em nossa sociedade e afirma que 
para garantir aos sujeitos modos de conduta socialmente adequados, é necessário potencializar o discurso hegemônico de modo a forçar uma identidade definitiva e, de alguma forma, tentar eliminar as "marcas" da diferença. Por isso, falar de identidade implica sempre falar de diferença. Toda e qualquer identidade é sempre construída pelo olhar minucioso sobre o outro, é constituída pelo que o outro não é. Assim, a identidade não implica somente positividade, mas está repleta de negatividade, pois é sempre a negação de marcas culturais que estão presentes na ausência.

Nessa obra, rompendo com o modo de conduta considerado satisfatório ao feminino, o casamento deixa de ser uma "solução natural". Uma visão assumidamente feminista, em que a mulher deixa de ser um "prêmio" destinado a outrem e passa a fazer escolhas e determinar sua vida amorosa.

A Princesa Sabichona tematiza a opressão da princesa ante a família que não lhe permite o direito de ser solteira. Percebe-se a desavença constante da personagem com sua mãe em prol da efetivação de seu maior desejo. Louro (1999, p. 13, grifo da autora) chama a atenção para que "a admissão de uma nova identidade sexual ou de uma nova identidade de gênero é considerada uma alteração essencial, uma alteração que atinge a 'essência' do sujeito".

Outro aspecto para análise dessa obra está na significação dos nomes escolhidos para os personagens masculinos: príncipes Adubo, Ousado, Roque, Tremelique, Tontura, Quebratudo, Mocotó, Rastejante, Mergulhão, Fanfarrão. Todos os dez receberam tarefas a serem cumpridas de acordo com seus nomes, como por exemplo, o Príncipe Mergulhão deveria retirar o anel mágico da princesa do tanque cheio de piranhas, o Príncipe Tremelique deveria andar com a prin-

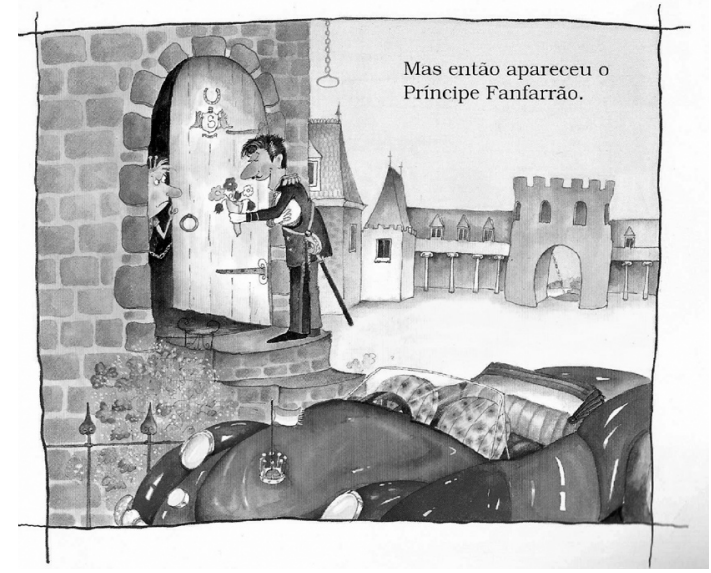
cesa de moto pelo campo, o Príncipe Tontura deveria resgatá-la do alto da torre... Enfim, a todos cabiam tarefas, determinadas pela protagonista, inexequíveis de realização com o objetivo único de não precisar unir-se ao pretendente. Chamo a atenção para o nome Fanfarrão. De todos eles, esse é que dá a ideia de farra, festa, diversão e, ao ser comparado com 
os demais, é o único príncipe que oferece flores à princesa cortejando-a, está bem penteado, não demonstra medo, confirmando as características masculinas presentes nos livros literários em geral.

Louro (2003, p. 44, grifo da autora) faz referência à posição central de sujeito dizendo que

ao conceito de centro vinculam-se, frequentemente, noções de universalidade, de unidade e de estabilidade. Os sujeitos e as práticas culturais que não ocupam este lugar recebem as marcas da particularidade, da diversidade e da instabilidade. Portanto, toda essa "conversa" pósmoderna de provisoriedade, precariedade, transitoriedade, etc. só pode se ajustar às mulheres, aos negros e negras, aos sujeitos homossexuais ou bissexuais. A identidade masculina, branca, heterossexual deve ser, supostamente, uma identidade sólida, permanente, uma referência confiável.

Conforme a contribuição da autora, se pode entender que os príncipes que "fugiam" de alguma forma da representação de masculinidade "central" não obtiveram sucesso em suas empreitadas, sendo reservado êxito somente àquele que atendia todos os "requisitos".

Na maior parte do texto, a narradora reforça que a princesa gosta de viver sossegada e fazer o que bem entende. Pode-se concluir com isso, que quem casa não consegue viver sossegado nem tampouco fazer o que bem entende. Dessa forma, uma vida prazerosa e "mais livre" seria reservada aos/às solteiros/as, pois casamento remete a compromisso, a regras, à falta de liberdade. Como Bauman (2004, p. 70) corrobora ao afirmar que o casamento é, "pode-se dizer, a aceitação da causalidade que os encontros casuais se recusam a aceitar (ou pelo menos uma declaração da intenção de aceitá-la - enquanto a união durar)".

Essa temática da mocinha não querer se casar, retratando o casamento como algo desinteressante para algumas pessoas e de elas serem felizes solteiras, é algo novo nas obras infantis, mas se encaixa nas paródias de Contos de Fadas, que emergiram tanto na literatura infantil brasileira quanto em outras literaturas, em que situações e personagens tradicionais são subvertidas e contestadas. A forma como a autora desenvolve a temática do enredo merece destaque no sentido de que usa do recurso do humor para versar sobre aspectos ainda não tão recorrentes em nossa literatura infanto-juvenil. Bergmann (2007), sobre isso, diz 
Para referir-se ao humor e ao cômico na Literatura Infantil, alguns autores de livros infantis brincam com as palavras, jogando com as mesmas $e$ usando rimas. Desta maneira, invertendo papéis dos personagens, tratam do inesperado e dão graça às situações propostas.

E esse recurso, o humor, nessa obra, alcança seu ápice em uma das cenas finais, quando o pretendente que conseguiu cumprir todas as tarefas estipuladas pela princesa, ao receber um beijo dela, transforma-se em sapo e, de tão decepcionado, vai embora a deixando solteira e feliz para sempre.

Por tais situações, percebe-se que se trata de uma obra cômica que se utiliza de conteúdos e formas (algumas) já conhecidas, brinca com elas, sem definir previamente o resultado. Contudo, ao chegar ao desfecho surpreendemo-nos com a astúcia e veemência da protagonista em conseguir se livrar do príncipe. Nessa situação, o masculino não é desejado nem o casamento é esperado como recompensa ao feminino, diferenciando-se da maioria das obras literárias
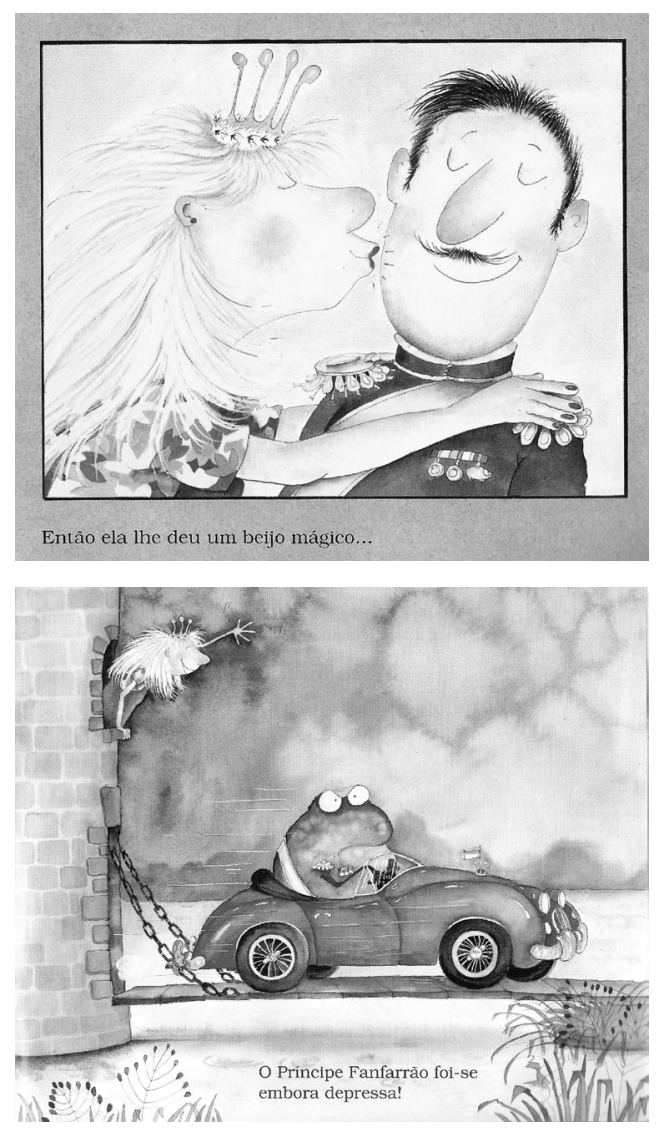
infantis. Dória (2008, p. 66) faz referência a isso quando afirma que: "A marca de tal criação é a liberdade: conceitos, verdades estabelecidas, estilos de narrar, tudo poderá ser remexido e alterado, e o resultado será sempre uma obra que faz pensar, choca, inova, ou simplesmente faz rir".

A possibilidade de ser feliz sem alguém ao lado definitivamente não faz parte dos discursos em torno do amor romântico na nossa sociedade. Até porque 
é atribuído(a) ao(à) parceiro(a) a responsabilidade de fazer o(a) outro(a) feliz e acompanhá-lo(a) até a velhice. Enquanto solteira, a pessoa já é vista com um certo estranhamento: aos homens é atribuída a desconfiança da homossexualidade e às mulheres, a probabilidade de serem pessoas difíceis de conviver, com um "gênio ruim" ou uma feiúra repulsiva.

Comumente, a forma de referir-se à mulher nas obras literárias infantis pode ser vista principalmente na representação visual das mães, pois elas são talhadas como exemplos de proteção, carinho e ternura. Frequentemente é associada a imagens femininas uma ideia leve, suave, meiga, comportada, como o tipo ideal de feminilidade. Em poucas histórias, como a citada, as mulheres já se arriscam a ter comportamentos explosivos, mostrando raiva, indignação, medo e indiferença, diferenciando-se da grande maioria.

Quero ressaltar que a crítica não se instaurou uma ação de encalço, condenando a autora e ilustradora dessa produção. Mesmo porque, cada texto expressa um momento do autor e cada obra pode ter diferentes interpretações que podem ser relacionadas a um contexto mais amplo. Todavia, saliento a importância de ter me reportado ao caso, com o intuito de instigar a percepção dos(as) leitores(as) sobre as representações presentes neste enredo a respeito das relações amorosas.

\section{REFERÊNCIAS}

ABRAMOVICH, Fanny. Literatura infantil: gostosuras e bobices. São Paulo: Scipione, 1997.

BAUMAN, Zygmunt. Amor líquido: sobre a fragilidade dos laços humanos. Tradução de: Carlos Alberto Medeiros. Rio de Janeiro: Jorge Zahar, 2004.

BERGMANN, Leila Mury. O humor na literatura infantil. Disponível em: $<\mathrm{http}: /$ www.unisinos.br/arte/files/educacao11(3)_art07_bergmann_sassi.pdf $>$. Acesso em: 17/12/2007.

COSTA, Jurandir Freire. Sem fraude nem favor. Estudos sobre o amor romântico. Rio de Janeiro: Rocco, 1998.

DÓRIA, Antonio Sampaio. O preconceito em foco: análise de obras literárias infantojuvenis: reflexões sobre história e cultura. São Paulo: Paulinas, 2008. 
FELIPE, Jane. Do amor (ou de como glamourizar a vida): apontamentos em torno de uma educação para a sexualidade. Trabalho apresentado no Seminário Corpo, Sexualidade e Gênero: discutindo práticas educativas, Porto Alegre, maio de 2006. 1 CD-ROM.

FOUCAULT, Michel. El orden del discurso. Barcelona: Tusquets, 1987.

HALL, Stuart. Representation: cultural representations and signifying practices. London: The Open University/ Sage publications, 1997.

. A identidade cultural na pós-modernidade. 2. ed. Rio de Janeiro: DP\&A, 1998.

LARROSA, Jorge. Narrativa, identidad y desidentificación. In: La experiencia de la lectura. Barcelona: Ed. Laertes,1996.

. Tecnologias do Eu e Educação. In: SILVA, Tomas Tadeu da (Org.). O Sujeito da Educação. Petrópolis: Vozes, 1999.

LOURO, Guacira Lopes. Pedagogias da Sexualidade. In: O Corpo Educado: pedagogias da sexualidade. Belo Horizonte: Autêntica, 1999.

. Currículo, gênero e sexualidade - O "normal", o "diferente" e o "excêntrico". In: LOURO, G.; NECKEL, Jane Felipe; GOELLNER, Silvana (Orgs.). Corpo, Gênero e Sexualidade. Petrópolis: Vozes, 2003.

PETERS, Michael. Pós-estruturalismo e filosofia da diferença. Tradução de: Tomas Tadeu da Silva. Belo Horizonte: Autêntica, 2000.

SABAT, Ruth. Só as bem quietinhas vão casar. In: MEYER, Dagmar Estermann; SOARES, Rosângela. Corpo, Gênero e Sexualidade. Porto Alegre: Mediação, 2004.

SILVEIRA, Rosa Maria Hessel; SANTOS, Cláudia Amaral dos. A problematização do gênero na literatura infantil: um estudo de caso no contexto brasileiro. CONGRESSO INTERNACIONAL CRIANÇA, LÍNGUA, IMAGINÁRIO E TEXTO LITERÁRIO, 2., 2006, Braga, Portugal. Atas... Portugal: Universidade do Minho, 2006. p. 1-9. 1 CD-ROM.

Texto recebido em 11 de junho de 2009.

Texto aprovado em 10 de julho de 2009. 